\title{
¿Hay una antropología en el Documento de Puebla? Mediaciones filosóficas subyacentes
}

\section{INTRODUCCIÓN}

¿Tendrá sentido estudiar desde el punto de vista filosófico la antropología del Documento de Puebla?

Hace una constatación el Concilio Vaticano II en la «Gaudium et Spes» (nn. 5 y 10). Las personas, los grupos sociales están sedientos de una vida plena y libre. Las aspiraciones más profundas y universales laten en las reivindicaciones que el hombre y el mundo de hoy hacen. En lo profundo de este hombre aparecen golpeando las preguntas: ¿Qué es el hombre? ¿Cuál es el sentido de la vida? ¿Qué puede dar a la sociedad y esperar de ella el hombre? ¿Qué hay después de esta vida temporal? ¿Qué sentido último tiene la acción humana en el universo?

La conclusión de la «Gaudium et Spes» es que la Iglesià, ante esta situación, debe colaborar con la humanidad a dar respuesta a estas interrogantes que tocan a lo más entrañable del ser del hombre. Y a pesar de que la misión de la Iglesia es religiosa, al empeñarse en esta tarea, resulta su acción plenamente humana.

Esto hace que merezca la pena analizar lo que se dice sobre el hombre latinoamericano en este Documento de Puebla, elaborado por la Tercera Conferencia General del Episcopado de América Latina.

La relación - no la confusión - entre la filosofía y la religión se puede entender mejor, quizá, observando la historia del pensamiento. La filosofía de Occidente, sobre todo, en la rama aristotélica y, después, claramente en la filosofía moderna, no aparece como una filosofía de salvación; es una filosofía laica en la cual el filósofo explica, razona pero con distancia de sí mismo. Por el contrario, en Oriente - nos referimos especialmente a las ramas originarias de la filosofía hindú - ha sido siempre su pecularidad, no solamente la 
información sino la transformación: un cambio radical de la naturaleza humana y, con él, una renovación de su manera de entender tanto en el mundo exterior como en su propia existencia. Supone una transformación tan completa como sea posible y que, si tiene éxito, corresponderá a una total conversión o renacimiento. Estas filosofías orientales, por tanto, pretenden, no simplemente una serie de conocimientos teóricos sino una forma de vivir y una forma más alta de ser.

Posiblemente nos acabe de orientar en la respuesta nada menos que Roger Garaudy, cuando recogiendo las frustraciones de la cultura de Occidente, estudia las manifestaciones colectivas de la relación con lo Trascendente y encuentra la afirmación constante de la inmanencia y trascendencia de Dios. Un Dios lejano y próximo a la vez que, en distintas etapas y maneras, - Los Vedas, los Upanisades, el Bhagavad Gita, etc., hasta el cristianismo- se presenta desde la Potencia indefinida a un Dios personal. La cultura Occidental ha obscurecido el sentido de la vida para muchos. Lo puramente racional, lo excesivamente lógico, lo técnico, el positivismo, el materialismo han ahogado la esperanza, la trascendencia, la creatividad, la estética, la intuición, lo experiencial, lo más allá de la estricta razón. La llamada al profetismo, a la utopía, al cristianismo de Garaudy puede darnos la clave para entender la relación entre la filosofía y el cristianismo. Sus palabras son reveladoras: «Este libro no ha sido escrito más que para trazar de nuevo el nacimiento de Dios en el hombre y del hombre en Dios» ${ }^{1}$.

En América Latina pululan diversas concepciones sobre el hombre. Resulta interesante, también, considerar lo que dice el cristianismo acerca del hombre, más todavía, si este hombre es visto, desde Latinoamérica por la Iglesia en el Documento de Puebla que quiere influenciar en la mentalidad de cientos de millones que se llaman católicos.

Nos importa ver qué antropología presenta el Documento de Puebla. Otro objetivo principal que nos proponemos es detectar qué relación tiene con la filosofía; qué mediaciones filosóficas utiliza para expresar su visión sobre el hombre: ¿Se adscribe a una corriente filosófica o, más bien, se expresa a través de las adquisiciones universales de las diversas filosofías que a la luz de la razón y de la fe le parecen más adecuadas para explicitar la visión que tiene del hombre y hacerse comprender con el lenguaje de hoy por el pueblo de América Latina?

En el capítulo primero hemos analizado los documentos eclesiásticos en los cuales tiene sus raíces y fundamento la antropología de Puebla.

1. R. Garaudy, Appel aux vivants, Edit. Seuil, Paris 1979, p. 65. 
El segundo capítulo se inicia estudiando, en el primer apartado, las palabras claves, con el fin de sacar a la luz las características de la antropología de Puebla y, al mismo tiempo, ponernos en pista para detectar las antropologías filosóficas de las cuales provienen. El apartado segundo presenta el tipo de antropología de Puebla. Se intenta, en el tercero, descubrir las mediaciones filosóficas subyacentes, buceando en el pensamiento teológico de las principales tendencias que hubo en Puebla para desvelar las filosofías que tienen como mediación y las antropologías que presuponen.

\section{CAPÍTULO I \\ CONTENIDO ANTROPOLÓGICO EN LOS DOCUMENTOS ECLESIÁSTICOS ANTERIORES A PUEBLA}

Los documentos que consideramos más importantes en relación con el tema son: La «Gaudium et Spes» del Vaticano II; La «Populorum Progressio», La «Octogesima Adveniens», La «Evangelii Nuntiandi» de Pablo VI; Los Documentos de Medellín.

\section{A) LA CONSTITUCión SOBRE LA IGLESIA EN EL MUNDO ACTUAL «GAUdiUM ET SPES»}

El Concilio Vaticano II es una fuente principal de la antropología de Puebla, tanto por las referencias que hace de él Puebla como por la comparación de ambos textos.

Las referencias se pueden ver en las notas del texto de Puebla. El documento fundamental del Vaticano II en el que se basa Puebla es la «Gaudium et Spes». Intentaremos analizarlo en una apretada síntesis.

Aquí, el Concilio recoge el giro antropológico de la teología, sobre todo, a partir de la generación de los teológos de la «Nueva teología» ${ }^{1}$. Se pone én-

1. C. Colombo, La metodologia e la sistemazione teologica, en Pontificia Facoltá Teologica di Milano, Problemi e orientamenti di Teologia Dogmatica, Carlo Marzorati-Editore, Milano, 1957, pp. 1-56; J. FeIner, J. Trüsch y otros, Panorama de la Teología actual, Edic. Guadarrama, Madrid 1961; L. REINISCH y otros, Teología actual, Edic. Guadarrama, Madrid 21964; T. PÉrEZ, 18 propulsores del Concilio, Edit. Paulinas, Madrid 1965; F. GABORIAU, El giro antropológico de la teología de hoy, Herder, Barcelona 1970, pp. 10-11; H. J. Schultz, Tendencias de la teología en el siglo XX. Una historia en semblanza, Studium, Madrid 1970; T. M. ScHoof, La nueva teología católica, Edic. Carlos Lohlé, Buenos Aires, 1971, pp. 187-275; J. SpERNA WeIland, La nueva teología protestante, Edic. Carlos Lohlé, Buenos Aires, 1971; A, MARRAnzini y otros, Correnti teologiche post-conciliari, Città Nuova Editrice, Roma 1974, p. 81; P. WATTE, Antropología teológica y hamartiología en el siglo $X X$, en $\mathrm{H}$. VORGRIMLER, R. VANDER GUCHT y otros, La teología en el siglo $X X$, BAC, 1974, pp. 47-63. 
fasis especial en el hombre concreto y en su realidad situacional como destinatario de la Palabra ${ }^{2}$. Al Concilio le preocupa salvar al hombre, pero a todo el hombre y, al mismo tiempo, al hombre concreto tal como se encuentra en el mundo de hoy ${ }^{3}$.

Lo primero que se destaca es un nuevo método: partir de la situación concreta del hombre ${ }^{4}$. Se parte de la situación del hombre pero para ser iluminada por la fe. No se trata de suplantar a las ciencias humanas sino de iluminar a la luz de la fe ${ }^{5}$.

Encontramos elementos importantes de una antropología cristiana. Parte del hombre todo y concreto pero para salvarlo ${ }^{6}$. Quiere conectar con él en sus aspiraciones más profundas para darle un sentido pleno. Un sentido de trascendencia en la inmanencia pero que, a la vez, le ayude a descubrir la salvación en Cristo por amor gratuito de Dios, en una correspondencia amorosa filial y fraterna por parte del hombre.

Es una antropología de salvación que toma como punto de partida lo humano en su ser personal, social, político, histórico para darle un sentido profundo, último; un sentido de salvación pero sin desencarnarlo de su ser en la historia ${ }^{7}$. «Es la persona del hombre la que hay que salvar. Es la sociedad humana la que hay que renovar» ${ }^{8}$. En la vocación del hombre se oculta la semilla divina y la fraternidad universal es un signo de esa semilla que la Iglesia quiere desarrollar, porque la Iglesia quiere salvar y no juzgar, servir y no ser servida ${ }^{9}$.

Para tener en cuenta a este hombre concreto y total en su situación histórica y poder dar una respuesta adecuada a la luz de la fe a los interrogantes más profundos que continuamente se ha hecho la humanidad a través de los siglos sobre «el sentido de la vida presente y de la vida futura y sobre la mutua relación de ambas», debe la Iglesia conocer los signos de los tiempos, com-

2. «Gaudium et Spes», n. 4. Para la Iglesia Católica, la Constitución «Gaudium et Spes» significa la postura antropológica eclesial más explícita. Cfr. J. GEVAERT, Antropología y catequesis, Edic. Don Bosco-CCS, Madrid 1975, p. 7.

3. Id., nn. 3-4.

4. Id., nn. 3, 4, 11 .

5. Id., nn. 3, 10, 11 .

6. Olga H. Haydar de Rosales, Hombres nuevos, Paulinas, Bogotá 1978, pp. 13 y 20. E. SCHILlebeECKx, La misión de la Iglesia, Salamanca 1971, p. 74; Y. CongAR, Cristo en la economía salvífica y en nuestros tratados de teología dogmática, en Rev. Concilium 2 (1966) 202.

7. «Gaudium et Spes», nn. 11, 44.

8. Id. n. 3 .

9. Id., nn. 3, 11; Leonardo BofF, El destino del hombre y del mundo. Ensayo sobre la vocación humana, Edit. Sal Terrae, Santander 1978, pp. 15-56, 178-1204; Marta BACHERER Soliz, Personalidad y valores religiosos. Función de éstos en la personalidad sana y neurótica, La Paz 1980 , p. 13. 
prender los problemas más profundos que se plantea el hombre, sus aspiraciones, sus dramas, la situación del mundo en que vive para buscar la luz del Evangelio que ayude a encontrar una orientación adecuada en el planteamiento $\mathrm{y}$ las soluciones a estos perennes interrogantes del hombre ${ }^{10}$.

Utiliza otro elemento importante en el método: no hace un análisis ideológico sino una constatación de hechos, en los cuales se ve envuelto y, es, al mismo tiempo en muchos casos, actor el hombre y la humanidad ${ }^{11}$. Se refiere a nivel general a los acontecimientos universales resaltantes que han causado en el hombre y en la humanidad «una verdadera metamorfosis social y cultural, que redunda también sobre la vida religiosa» ${ }^{12}$. También destaca las consecuencias positivas que personalizan al hombre y las negativas que lo deshumanizan ${ }^{13}$.

En conclusión, la Iglesia considera que lo religioso y la concepción cristiana del hombre es parte integrante y esencial de lo humano, del hombre. Por eso quiere iluminar lo humáno con lo religioso para plenificar la antropología, especialmente la filosófica, que es el punto de vista que más nos interesa:

Pero bajo todas estas reivindicaciones se oculta una aspiración más profunda y más universal: las personas y los grupos sociales están sedientos de una vida plena y de una vida libre, digna del hombre, poniendo a su servicio las inmensas posibilidades que les ofrece el mundo actual. Las naciones, por otra parte, se esfuerzan cada vez más por formar una comunidad universal ${ }^{14}$.

En lo más íntimo del hombre de hoy palpitan las cuestiones más fundamentales del ser del hombre y subyace en su corazón una apertura que conecta con la plenitud de Cristo:

Sin embargo, ante la actual evolución del mundo, son cada día más numerosos los que se plantean o los que acometen con nueva penetración las cuestiones más fundamentales: ¿Qué es el hombre? ¿Cuál es el sentido del dolor, del mal, de la muerte, que, a pesar de tantos progresos hechos subsiste todavía? ¿Qué valor tienen las victorias logradas a tan caro precio? ¿Qué puede dar el hombre a la sociedad? ¿Qué puede esperar de ella? ¿Qué hay después de esta vida temporal?

...Bajo la luz de Cristo, imagen de Dios invisible, primogénito de toda creación, el Concilio habla a todos para esclarecer el misterio del hombre y para cooperar en el hallazgo de soluciones que respondan a los principales problemas de nuestra época ${ }^{15}$.

10. «Gaudium et Spes», nn. 4, 9, 10.

11. Id., n. 4 .

12. Id., nn. 4, 5 .

13. Id., nn. $6,7,9$.

14. Id., n. 5 .

15. Id., n. 10. 
...¿Qué sentido último tiene la acción humana en el universo? He aquí las preguntas que aguardan respuesta. Esta hará ver con claridad que el Pueblo de Dios y la humanidad, de la que aquel forma parte, se prestan mutuo servicio, lo cual demuestra que la misión de la Iglesia es religiosa y, por lo mismo, plenamente humana ${ }^{16}$,

El método de la «Gaudium et Spes» es de una antropología teológica, pudiéramos decir. O sea, parte del hombre y su situación, del aporte de las ciencias humanas para buscar la conexión con la visión cristiana sobre el hombre, de tal forma que no aparezca una superposición sino una plenificación del hombre.

El método, por tanto, está claro. Los contenidos antropológicos se reducen a puntos simples: El hombre en sí; el hombre en la comunidad social; el hombre en la historia; el hombre, la Iglesia y el mundo.

\section{El hombre en sí}

El concilio parte de la vocación del hombre y después se adentra en su constitución.

En lo más profundo del ser del hombre están enraizadas unas interpelaciones y unas aspiraciones que lo lanzan hacia la búsqueda de respuestas totales que puedan acallar esa inquietud insatisfecha que late en todo hombre consciente: «Como criatura, el hombre experimenta múltiples limitaciones; se siente, sin embargo ilimitado en sus deseos y llamado a una vida superior» ${ }^{17}$.

A pesar de que hay muchos que se dan respuestas vanales y fútiles y otros, con la mejor buena voluntad, se dan respuestas falsas, sin embargo, hay cada vez más hombres que se plantean y acometen la tarea de dar respuesta a las interpelaciones más fundamentales que se les plantea en lo más esencial de su existir ${ }^{18}$.

El hombre no sólo se interpela a sí mismo sino que siente con toda la humanidad las aspiraciones del género humano:

Entre tanto, se afianza la convicción de que el género humano puede y debe no sólo perfeccionar su dominio sobre las cosas creadas, sino que le corresponde además establecer un orden político, económico y social que esté más al servicio del hombre y permita a cada uno y a cada grupo afirmar y cultivar su propia dignidad ${ }^{19}$.

16. Id., n. 11.

17. Id. n. 10 .

18. «¿Qué es el hombre? ¿Cuál es el sentido del dolor, del mal, de la muerte, que, a pesar de tantos progresos hechos, subsisten todavía? ¿Qué precio? ¿Qué puede dar el hombre a la sociedad? ¿Qué hay después de esta vida temporal?, Cfr. Id., n. 10.

19. Id., n. 9. 
Lo que subyace en todo esto, es la aspiración universal a una vida plena y libre, digna del hombre, donde la fraternidad, la justicia y la libertad tanto en las relaciones interpersonales como en las relaciones entre las naciones sea un hecho ${ }^{20}$. Y entonces, la pregunta clave se hace presente ¿Cuál es el sentido último del hombre y del universo? ¿Cuál es la vocación del hombre?

Aquí es donde quiere conectar la antropología cristiana con las antropologías filosóficas:

El Pueblo de Dios, movido por la fe, que le impulsa a creer que quien lo conduce es el Espíritu del Señor, que llena el universo, procura discernir en los acontecimientos, exigencias y deseos, de los cuales participa juntamente con sus contemporáneos, los signos verdaderos de la presencia o de los planes de Dios. La fe todo lo ilumina con nueva luz y manifiesta el plan divino sobre la entera vocación del hombre. Por ello orienta la mente hacia soluciones plenamente humanas.

El Concilio se propone, ante todo, juzgar bajo esta luz los valores que hoy disfrutan de máxima consideración y enlazarlos de nuevo con su fuente divina ${ }^{21}$.

La vocación es el principio de unión, con el cual, quiere engarzar el plan de Dios. La inteligencia humana recta distingue los valores auténticos y, sobre lo natural, sin superposiciones, quiere la Iglesia ayudar a clarificar el sentido último del hombre con la ayuda de la fe. Así, presta un servicio plenamente humano porque intenta colaborar en la respuesta a un problema, tan inquietante y profundo como es el sentido último del hombre y de su actuar en la sociedad y en el universo. No pretende una respuesta mágica, por tanto, sino plenamente humana porque quiere dar respuesta total a las preguntas que intranquilizan lo más recóndito del hombre y de la humanidad.

El otro elemento que salta a la vista en la consideración del hombre, y en relación con la vocación en la «Gaudium et Spes», es la constitución del hombre ${ }^{22}$. Resalta el abandono de una concepción esencialista y estática en

20. Ib.

21. Id., n. 11. Las palabras que continúan en este número completan el sentido de la vocación del hombre y la respuesta con que la Iglesia quiere contribuir a esclarecer el sentido último del hombre: «Estos valores, por proceder de la inteligencia que Dios ha dado al hombre, poseen una bondad extraordinaria; pero a causa de la corrupción del corazón humano, sufren con frecuencia desviaciones contrarias a su debida ordenación. Por ello necesitan perfeccionamiento. ¿Qué piensa del hombre la Iglesia? ¿Qué criterios fundamentales deben recomendarse para levantar el edificio de la sociedad actual? ¿Qué sentido último tiene la acción humana en el universo? He aquí las preguntas que aguardan respuesta... el Pueblo de Dios y la humanidad..., se prestan mutuo servicio, lo cual demuestra que la misión de la Iglesia es religiosa y, por lo mismo, plenamente humana».

22. En la constitución del hombre subyacen las preguntas claves sobre lo esencial de la antropología: «...Lo que inquieta a los filósofos no es el problema que plantea la aparición del «homo sapiens», sino el problema que tiene el «homo sapiens»; es decir, el verdadero problema de los 
favor de una visión existencial, dinámina, histórica ${ }^{23}$. Y se centra el tema en que la dignidad del hombre, además, de provenirle por el hecho de ser hombre en su situación histórica, tiene su fundamento principal en ser imagen de Dios ${ }^{24}$. Después, resalta las cualidades que adornan el ser humano, mezclando lo filosófico y lo religioso con lo cual sigue la línea de una antropología que hemos llamado antropología teológica, cristiana o de salvación. Considera el Concilio que ésta es la vía más adecuada para dialogar y colaborar en lo más importante con el hombre y el mundo de hoy que es «...conocer simultáneamente y con acierto la dignidad y la vocación propias del hombre» ${ }^{25}$.

Entre las características que resalta, además de la de ser imagen de Dios, es que es ser social por naturaleza y le es propio relacionarse con los demás para ser persona ${ }^{26}$. Sin embargo hay un elemento negativo que es el pecado. Este pecado que supone un drama en el hombre, porque no solamente atenta contra Dios, sino contra su misma dignidad, contra su vocación, contra su propia plenitud y, precisamente: «A la luz de esta Revelación, la sublime vocación y la miseria profunda que el hombre experimenta hallan simultáneamente su última explicación» ${ }^{25}$.

Rompe el dualismo maniqueo y propicia el principio del alma encarnada, no cuerpo animado. Pero esta constitución no dualista sino unitaria de cuerpo y alma, hace que el hombre, además de ser inmanente, esté abierto a lo trascendente, a lo espiritual, a lo inmortal ${ }^{26}$.

Por la inteligencia busca la verdad y descubre el bien y encuentra su plenitud vislumbrando el plan divino: «Con el don del Espíritu Santo, el hombre llega por la fe a contemplar y saborear el misterio del plan divino» ${ }^{27}$.

Supone una ética que tiene su complemento en la moral cristiana. El pecado rebaja al hombre impidiéndole lograr su propia plenitud. Por eso, la libertad, la muerte, el respeto a la persona, la solidaridad y fraternidad, la igualdad y la justicia social, la responsabilidad y la participación, la superación de una ética individualista, tienen en el Verbo Encarnado la motivación suprema, el ejemplo, el modelo, la plenitud del hombre nuevo ${ }^{28}$.

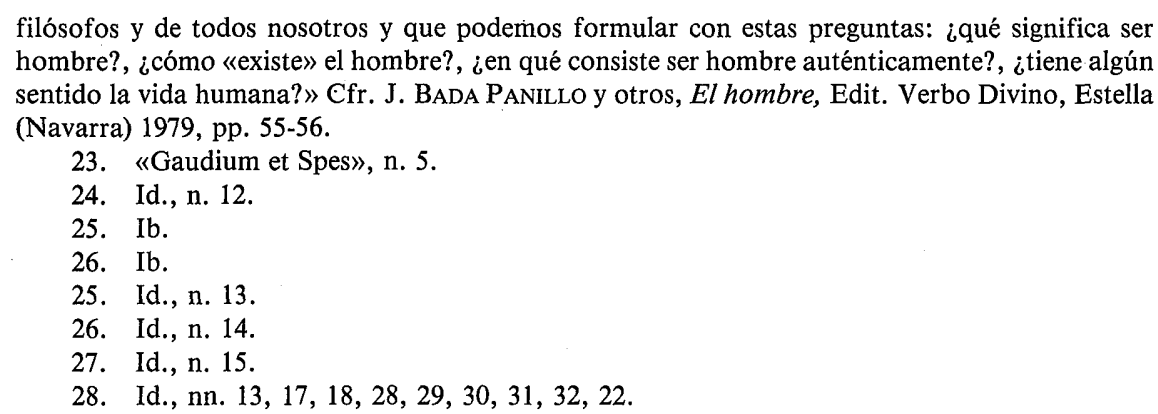


Al referirnos al hombre, por lo tanto, hay que tener en cuenta, según los planteamientos de la «Gaudium et Spes», la vocación y la constitución del hombre, como hemos visto. Pero, a continuación nos hace adentrarnos en otro punto antropológico: el hombre no es un ser solitario sino que está hecho para la comunidad social.

\section{El hombre en la comunidad social}

La antropología del Concilio no descuida este punto y señala, claramente, la necesidad de las relaciones interpersonales que deben llevar a una auténtica comunidad de personas por ser el hombre un ser social por naturaleza. Tendrá como precepto intangible el respeto mutuo - basado en la dignidad del hombre-, porque de ahí emanarán las leyes, las leyes justas que deberán estar en favor de la naturaleza humana, ya que el Creador ha insertado en la vida del hombre y en las relaciones sociales la justicia y la armonía ${ }^{29}$.

Se parte de la índole comunitaria del hombre según la razón y el plan de Dios ${ }^{30}$. Se trata de esclarecer la interdependencia entre la persona humana y la sociedad, de tal forma que, la sociedad será comunidad, en la medida en que ayuda a crecer a la persona, porque debe colocarla como el principio, sujeto y fin de todas las instituciones $\mathrm{y}$, asimismo, la persona humana se desarrolla en la medida en que se entrega al servicio de la comunidad social ${ }^{31}$. El sentido cristiano debe ayudar para que se pongan los esfuerzos adecuados para cumplir estos propósitos. Quizá, así, las perturbaciones sociales originadas, en parte, por las estructuras económicas, políticas y sociales y, en otra, por la soberbia y egoísmo del hombre, puedan superarse si se agudiza la conciencia cristiana de caridad y de justicia, tanto en la persona como en la sociedad ${ }^{32}$.

29. «...Sin embargo, la perfección del coloquio fraterno no está en ese progreso, sino más hondamente en la comunidad que entre las personas se establece, la cual exige el mutuo respeto de su plena dignidad espiritual. La Revelación cristiana presta gran ayuda para fomentar esta comunión interpersonal y al mismo tiempo nos lleva a una más profunda comprensión de las leyes que regulan la vida social, y que el Creador grabó en la naturaleza espiritual y moral del hombre». Cfr. «Gaudium et Spes», n. 23.

30. «Dios, que cuida de todos con paterna solicitud, ha querido que los hombres constituyan una sola familia y se traten entre sí con espíritu de hermanos.

...el hombre..., no puede encontrar su propia plenitud si no es en la entrega sincera de sí mismo a los demás». Cfr ، Id., n. 24.

31. «La índole social del hombre demuestra que el desarrollo de la persona humana y el crecimiento de la propia sociedad están mutuamente condicionados. Porque el principio, el sujeto y el fin de todas las instituciones sociales es y debe ser la persona humana, la cual, por su misma naturaleza, tiene absoluta necesidad de la vida social». Cfr. Id., n. 25.

32. «El orden social, pues, y su progresivo desarrollo deben en todo momento subordinarse al bien de la persona, ya que el orden real debe someterse al orden personal, y no al contrario... El orden social hay que desarrollarlo a diario, fundarlo en la verdad, edificarlo sobre la justicia, vivi- 
La promoción del bien común es una consecuencia lógica de este sentido comunitario, así como el respeto a la persona humana, el respeto y amor a los adversarios, la igualdad esencial entre los hombres y la justicia social, la superación de una eticidad individualista por exigencias de justicia y caridad, la responsabilidad y la participación ${ }^{33}$. Si a esto se añade la suprema motivación del ejemplo de solidaridad, amor, justicia y generosidad del Verbo Encarnado y nos miramos en el espejo de Cristo, lograremos esfuerzos eficaces para construir una auténtica comunidad humana ${ }^{34}$.

\section{El hombre en la historia}

El hombre es un ser personal en la historia y es proyectivo, trascendente.

Existimos en las coordenadas tiempo-espacio que nos marcan nuestra situación. Somos seres situados, seres en el mundo. Vivimos por esencia en comunicación con el mundo, en lugar y en tiempo determinado que nos sitúan en la historia en forma autónoma. El hombre está en la realidad terrena con justa autonomía. La religión no solamente no debe poner trabas, sino que se compromete a activar el progreso del hombre, de la sociedad, de la ciencia:

Si por autonomía de la realidad terrena se quiere decir que las cosas creadas y la sociedad misma gozan de propias leyes y valores, que el hombre ha de descubrir, emplear y ordenar poco a poco, es absolutamente legítima esta exigencia de autonomía... Es que además responde a la voluntad del Creador. Pues, por la propia naturaleza de la creación, todas las cosas están dotadas de consistencia, verdad y bondad propias y de un propio orden regulado, que el hombre debe respetar con el reconocimiento de la metodología particular de cada ciencia o arte ${ }^{35}$.

Sin embargo, hay que tener en cuenta, también, que esta autonomía de lo temporal no tiene por qué estar cerrada a lo trascendente, en último término, a su Creador:

Pero si autonomía de lo temporal quiere decir que la realidad creada es independiente de Dios y que los hombres pueden usarla sin referencia al Creador, no hay creyente alguno a quien se le escape la falsedad envuelta en tales palabras. La criatura sin el Creador desaparece. Por lo demás, cuantos creen en Dios, sea cual fuere su religión, escucharon siempre la manifestación de la voz de Dios en el lenguaje de la creación. Más aún, por el olvido de Dios la propia criatura queda oscurecida ${ }^{36}$.

ficarlo por el amor... en libertad un equilibrio cada día más humano... proceder a una renovación de espíritus y a profundas reformas de la sociedad». Cfr. Id., n. 26.

33. Id., nn. 26-31.

34. Id., n. 32 .

35. Id., n. 36.

36. Ib. 
Se cierne siempre un peligro sobre el deambular histórico del hombre que se debe procurar evitar: es el desorden ético. Éste incita continuamente al hombre a servirse de lo ajeno en utilidad propia, en lugar de buscar el bien y lo bueno, de tal forma que, haga de esta historia una habitación donde reine la felicidad humana ${ }^{37}$.

Decíamos que, además, el hombre es proyectivo, trascendente, pudiéramos decir, que es un ser-hacia. Tiene capacidad de trascender, de perfeccionar la vida, de ir más lejos, de no conformarse con lo dado; determina la persona y dilata sus dominios sobre los más variados campos de la naturaleza. Hace progresar al hombre y al mundo. Significa, en consecuencia, que el hombre -la persona- y el mundo son un proyecto, no algo ya hecho. Solamente el hombre es capaz de salir de sí mismo, de inventar, de proyectar sobre las cosas y sobre sí mismo: «...De lo que resulta que gran número de bienes que antes el hombre esperaba alcanzar sobre todo de las fuerzas superiores, hoy los obtiene por sí mismo» ${ }^{38}$. Por eso, todo hombre consciente, viéndose ante este cúmulo de posibilidades, se hace preguntas tan graves como: «¿Qué sentido y valor tiene esa actividad? ¿Cuál es el uso que hay que hacer de todas estas cosas? ¿A qué fin deben tender los esfuerzos de los individuos y colectividades?» ${ }^{39}$. A la respuesta a estas preguntas, quiere colaborar la Iglesia, conjugando el saber humano con la luz de la Revelación, para lograr el cumplimiento de los designios de Dios en la historia.

El cultivo de las facultades del hombre, el progreso, el desarrollo, la transformación del mundo deben encaminarse a la personalización del hombre. El Vaticano II establece la gran norma: «...El hombre vale más por lo que es que por lo que tiene», a nivel de persona y, a nivel de historia: «...cuanto llevan a cabo los hombres para lograr más justicia, mayor fraternidad y un más humano planteamiento en los problemas sociales, vale más que los progresos técnicos» ${ }^{40}$.

37. «La Sagrada Escritura, con quien está de acuerdo la experiencia de los siglos, enseña a la familia humana que el progreso altamente beneficioso para el hombre también encierra, sin embargo, gran tentación, pues los individuos y las colectividades, subvertida la jerarquía de los valores y mezclando el bien con el mal, no miran más que a lo suyo, olvidando lo ajeno. Lo que hace que el mundo no sea ya ámbito de una auténtica fraternidad, mientras el poder acrecido de la humanidad está amenazando con destruir el propio género humano». Cfr. «Gaudium et Spes», n. 37.

38. Id., n. 33 .

39. Ib.

40. «Gaudium et Spes», n. 35; «...Pues dichos progresos pueden ofrecer, como si dijéramos, el material pará la promoción humana, pero por sí solos no pueden llevarla a cabo.

Por tanto, esta es la norma de la actividad humana: que de acuerdo con los designios y voluntad divinos, sea conforme al auténtico bien del género humano y permita al hombre, como individuo y como miembro de la sociedad, cultivar y realizar íntegramente su plena vocación». Cfr. Ib. 
Con este actuar humano recto, tanto en lo personal como en el mundo, se logrará la meta del «cielo nuevo» y la «tierra nueva», cuyo motor, activador, modelo y fin, para los cristianos y para los hombres de buena voluntad, lo tenemos en Cristo: «El Verbo de Dios, por quien fueron hechas todas las cosas, hecho él mismo carne y habitando en la tierra, entró como hombre perfecto en la historia del mundo, asumiéndola y recapitulándola en sí mismo» ${ }^{41}$. El medio con el cual se logra el perfeccionamiento del hombre y del mundo es el amor del cual Cristo es el primer abanderado: «...Él es quien nos revela que Dios es amor (1Jn 4,8), a la vez que nos enseña que la ley fundamental de la perfección humana, y, por tanto, de la transformación del mundo, es el mandamiento nuevo del amor» ${ }^{42}$.

Sin embargo, hay que recalcar que este Cristo, Señor de la historia, «alfa y omega» y promotor de esta historia, respeta al máximo la libertad del hombre y la autonomía de las realidades terrestres; por eso, no se puede disolver o encasillar el reino de Cristo, en ideologías, sistemas o proyectos humanos aunque éstos sean los medios que favorezcan la realización del reino de Dios en la historia: «...Por ello, aunque hay que distinguir cuidadosamente, progreso temporal y crecimiento del reino de Cristo, sin embargo, el primero, en cuanto puede contribuir a ordenar mejor la sociedad humana, interesa en gran medida al reino de Dios» ${ }^{43}$.

Así, la autonomía de lo temporal, sobre la que se proyecta libremente el hombre con un inmenso abanico de posibilidades, debe ser para convertir a esta historia en más humana y a este hombre en más persona con proyecciones totalmente abiertas para dar cabida a Dios y a sus promesas presentes y futuras ${ }^{44}$.

\section{El hombre, la sociedad, la historia y la Iglesia: hermenéutica antropológica}

Aunque la Iglesia tiene una finalidad espiritual no hace dicotomía incompatible con lo temporal, sino que da y recibe ayuda en un intercambio enriquecedor ${ }^{45}$. La Iglesia existe en este mundo, vive y actúa con él. Tiene una relación insoslayable con el hombre, con la sociedad, con la historia y una finalidad bien concreta: lograr que los hombres hagan en esta historia humana la familia de los hijos de Dios y, al mismo tiempo la razón de ser de ella está en actuar como fermento y como alma de la sociedad y de la historia, «que debe renovarse en Cristo y transformarse en familia de Dios» ${ }^{46}$.

41. Id., $\mathrm{nn} .38,39$.

42. Id., n. 38 .

43. Id., n. 39 .

44. Ib.

45. "Gaudium et Spes», n. 40 .

46. $\mathrm{Ib}$. «Al buscar su propio fin de salvación, la Iglesia no sólo comunica la vida divina al 
Ayuda al hombre a descubrir el sentido de la propia existencia, la verdad más profunda del ser humano:

«...No hay ley humana que pueda garantizar la dignidad personal y la libertad del hombre con la seguridad que comunica el Evangelio de Cristo, confiado a la Iglesia. El Evangelio anuncia y proclama la libertad de los hijos de Dios, rechaza todas las esclavitudes...; respeta santamente la dignidad de la conciencia y su libre decisión; advierte sin cesar que todo talento humano debe redundar en servicio de Dios y bien de la humanidad; encomienda, finalmente, a todos la caridad de todos. Esto corresponde a la ley fundamental de la economía cristiana. Porque, aunque el mismo Dios es Salvador y Creador, e igualmente Señor de la historia humana y de la historia de la salvación, sin embargo, en esta misma ordenación divina la justa autonomía de lo creado, y sobre todo del hombre, no se suprime, sino que más bien se restituye a su propia dignidad y se ve en ella consolidada ${ }^{47}$.

La dignidad del hombre y las cualidades que adornan la constitución del hombre se ven ensalzadas en grado sumo en este texto. Se respeta el ser hombre y su justa autonomía, pero, a la vez, se le ayuda a salir de sí mismo, a abrirse a los demás y a clarificar la motivación divina que subyace en él.

Por otra parte, no solamente ayuda al hombre, sino que da sentido a la sociedad, pues da la auténtica motivación a las relaciones interpersonales fraternas, caritativas y justas que deben existir en la sociedad que intenta hoy la comunidad humana: «...Enseña así al mundo que la genuina unión social exterior procede de la unión de los espíritus y de los corazones, esto es, de la fe y de la caridad, que constituyen el fundamento indisoluble de su unidad en el Espíritu Santo» ${ }^{48}$.

Es, además, la Iglesia activadora de la historia. Promueve, motiva a los cristianos y a los hombres de buena voluntad para cumplir con los deberes temporales y actuar en la historia guiados por los valores, por el espíritu evangélico ${ }^{49}$. Llama la atención, inclusive, a los espiritualistas para que rompan la dicotomía temporal-eterno y se dediquen a las cosas temporales, sin olvidarse de lo eterno: «...El cristiano que falta a sus obligaciones temporales, falta a sus deberes con el prójimo; falta, sobre todo, a sus obligaciones para con Dios y pone en peligro su eterna salvación» ${ }^{50}$. Del mismo modo, amones-

hombre, sino que además difunde sobre el universo mundo, en cierto modo el reflejo de su luz, sobre todo curando y elevando la dignidad de la persona, consolidando la firmeza de la sociedad y dotando a la actividad diaria de la humanidad de un sentido y una significación mucho más profundos. Cree la Iglesia que de esta manera, por medio de sus hijos y de su entera comunidad, puede ofrecer gran ayuda para dar un sentido más humano al hombre y a su historia». Cfr. Ib.

47. «Gaudium et Spes», nn. 41, 40, 44.

48. Id., n. 42 .

49. Id., n. 40 .

50. Id., n. 43. 
ta, también, al que se enfrasca en lo puramente inmanente, olvidando su vocación trascendente.

La finalidad de la actuación de la Iglesia en la historia es: «...el advenimiento del reino de Dios y la salvación de toda la humanidad» ${ }^{51}$. No debe estar ligada a ninguna civilización ni a ningún sistema. Así, podrá y deberá desarrollar una actitud crítica y orientadora en la historia a la luz de la fe ${ }^{52}$. Lo que es propio de ella es la motivación evangélica; las diversas soluciones políticas, sociales, económicas no le competen a ella; los proyectos pueden ser diversos. Sin embargo, su actitud es activa: incita a los cristianos a elegir o buscar sistemas, ideologías que no sean incompatibles con el mensaje evangélico, pues corresponde a los hombres hacer de nuestra historia una historia de salvación donde impere el reino de Dios ${ }^{53}$.

Hay que tener en cuenta que la Iglesia, el mensaje que ella transmite, no solamente ayuda, sino que, también, recibe un intercambio enriquecedor de la historia ${ }^{54}$. Evidentemente, las ciencias humanas ayudan a clarificar la naturaleza del hombre en todas sus dimensiones. Esto ayuda sobremanera al mensaje evangélico en la compresión del hombre y su ser en la historia. Pero, sin embargo, el reino de Dios no se disuelve en la historia porque no es una ideología, un sistema. Utiliza y está continuamente impulsando a la búsqueda de sistemas e ideologías que sirvan de auténticos mediadores en la construcción del reino de Dios en la historia.

Los documentos de la Iglesia, como lo es la «Gaudium et Spes» que estamos analizando, no son una teología ni una filosofía:

«...Pues bien, jamás el Magisterio, en un acto oficial, opta por una teología católica frente a otra, ni para condenarla ni para canonizarla. Los Obispos Congregados son testigos de la palabra de Dios; no actúan nunca como teólogos (aun cuando lo sean), sino como pre-teólogos, en el sentido de que, interpretando la revelación fundan o ponen en marcha la teología ${ }^{55}$.

De lo que se trata en los documentos eclesiales es de transmitir el mensaje de Cristo, presentarlo, llamar la atención sobre ciertos puntos concretos. Pero

51. Id., n. 45 .

52. Id., n. 42 .

53. Id., nn. 43, 42 .

54. «La experiencia del pasado, el progreso científico, los tesoros escondidos en las diversas culturas, permiten conocer más a fondo la naturaleza humana, abren nuevos caminos para la verdad y aprovechan también a la Iglesia. Ésta desde el comienzo de su historia, aprendió a expresar el mensaje cristiano con los conceptos y en la lengua de cada pueblo y procuró ilustrarlo además con el saber filosófico. Procedió así a fin de adaptar el Evangelio al nivel del saber popular y a las exigencias de los sabios en cuanto era posible». Cfr. Id., n. 44.

55. F. Interdonato, Teología latinoamericana. ¿Teología de la libertación?, Edic. Paulinas, Bogotá 1979, p. 154. 
aunque no quieren hacer teología ni filosofía, sin embargo, utilizan un lenguaje y unos conceptos para transmitir el mensaje de Jesús que corresponden, ordinariamente, al pensamiento dominante en la época del documento ${ }^{56}$. El Concilio vaticano II, por ejemplo, utiliza predominantemente un lenguaje teológico en el cual subyace una filosofía personalista:

«El Vaticano II..., comienza a sustituir esa mentalidad greco-romana por la que impone el personalismo evangélico y el personalismo y universalismo de las ciencias humanas actuales, es decir: por una teología de relaciones interpersonales entre Dios y los hombres. Además de ese universalismo de la magna historia de la salvación, cuyo signo por excelencia es la comunión.... ${ }^{57}$.

En otros documentos, quizás, aparece una especie de sincretismo en la mediación del lenguaje, debido a las concesiones, que se necesitan hacer para poder coordinar las diversas mentalidades que existen y, poder llegar, así, a la elaboración del documento ${ }^{58}$.

Aquí se plantea un problema que venía latiendo a través de nuestro estudio: la hermenéutica antropológica de la «Gaudium et Spes».

El giro antropológico que le daba a la teología un cariz existencial, dinámico, en la historia, se nota acá en un giro cristocéntrico. De Dios, punto culmen de interpretación, se pasa al Dios Encarnado, al Verbo, a Cristo. De un teocentrismo se pasa a una antropología cristocéntrica, dando a la antropología de salvación, un sentido existencial, dinámico, en la historia ${ }^{59}$.

56. «...Hay que hacer todo lo posible para que los lectores no confundan el mensaje de Jesús con posibles posturas pasajeras, incluso de los Papas, cuando procedan únicamente de su formación filosófica y de su temperamento o del medio ambiente en que han desarrollado su actividad pastoral. El Magisterio de la Iglesia en las encíclicas de los Papas y a otro nivel en las cartas pastorales de los obispos, suelen tener como finalidad llamar la atención sobre algún problema específico del momento o del lugar y a veces son llamadas de alerta ante peligros contra la fe, que ellos creen fundadas. Pero, en cuento tales, no puede decirse que en esos documentos hagan propiamente teología, es decir: una reflexión sistemática (de algún modo) sobre Jesús y su experiencia humano-religiosa a base de filosofías, las culturas y la mentalidad en general de las distintas épocas y lugares. «Cfr. A. TURRADO, De Juan XXIII a Juan Pablo II. Reflexiones en torno a la raíz de su postura doctrinal y práctica, en Rev. Agust. de Espiritualidad, nn. 61-62 (1979) 27-28.

57. Id., ib. p. 55.

58. Joaquín GARCía, Fe, cultura e indigenismo en el Documento de Puebla, en Rev. Shupihui, Publicaciones CETA, Iquitos (Perú), vol. IV, n. 9 (1979) 24-25.

59. «...No se pasó de la antropología de un sujeto cognoscente cuya relación viva con Cristo sólo se enfocaba de la óptica de la relación con Dios, autor lo mismo de la gracia que de la naturaleza...

La vieja problemática de una esencia del hombre, idéntica a sí misma en cuanquier fase de su evolución, se ve sacudida ahora por la irrupción de la historia, de una historia profundamente crística. Los tratados de principios de este siglo consideran la fe desde la óptica de la razón humana; ahora se define históricamente a la razón humana a partir de la referencia a Cristo dada en la fe». Cfr. Pierre WATTE, Antropología teológica y hamartiología en el siglo $X X$, en H. VoRGRIMLER y otros, La teología en el siglo XX. III, BAC, Madrid 1974, p. 52. 
La hermenéutica antropológica de la «Gaudium et Spes» supone interpretar la concepción del hombre y su situación social e histórica a la luz de Cristo, para activar la participación del cristiano en esta historia espaciotemporal, bajo la iluminación de los valores evangélicos. Si Cristo es el camino, la verdad y la vida, el misterio de Cristo es el que podrá clarificar el misterio del hombre y su actuar en los diversos proyectos posibles para dar respuesta adecuada a las exigencias de la sociedad y del universo. La elección entre las posibles soluciones le toca al hombre, pero la luz, el criterio para el cristiano es el mensaje evangélico, es en último término, Cristo ${ }^{60}$.

La metodología supone una hermenéutica y, a su vez, subyace en ésta una teoría del conocimiento ${ }^{61}$. Ya vimos la metodología: se parte del hombre y su situación para conectar con la concepción cristiana. A través del estudio, rápidamente se intuye el principio hermenéutico en el que se apoya la antropología de la Constitución sobre la Iglesia en el mundo actual: Cristo. Las mediaciones que son utilizadas para trasmitir la visión cristiana del hombre, como son los conceptos y el lenguaje de cada pueblo, el saber popular y el saber filosófico, están al servicio y son juzgadas según criterios evangélicos:

Es propio de todo el Pueblo de Dios, pero principalmente de los pastores y de los teólogos, auscultar, discernir e interpretar, con la ayuda del Espíritu Santo, las múltiples voces de nuestro tiempo y valorarlas a la luz de la palabra divina, a fin de que la Verdad revelada pueda ser mejor percibida, mejor entendida y expresada en forma más adecuada ${ }^{62}$.

Pero, en último término, esa luz de la palabra divina, donde se concentra el criterio supremo hermenéutico, quién es el fundamento último tiene un nombre: Cristo, alfa y omega ${ }^{63}$. Aquí queda al descubierto el hilo central de

60. «La misión propia que Cristo confió a su Iglesia no es de orden político, económico o social. El fin que le asignó es de orden religioso. Pero precisamente de esta misión religiosa deriva funciones, luces y energías que pueden servir para establecer y consolidar la comunidad humana según la ley divina». Cfr. «Gaudium et Spes», n. 42.

61. I. M. Bochenski, Los métodos actuales del pensamiento, Edic. Rialp, Madrid ${ }^{13} 1979$; Umberto Eco, Lector de fábula, Bompiani, Milano 1979, pp. 13-49; H.-G. GADAMER, Verdad y método, Sígueme, Salamanca 1977, pp. 331-586; A. PARRA, Fe e interpretaciones de la fe. -Una introducción a la hermenéutica teológica-, Bogotá 1976, p. 24; F. MARCOS MARÍN, Lingüística y lengua española, Edit. Cincel, Madrid 1975, pp. 37-64; J.-P. RESEBER, La Theologiae face au défit hermeneutique, Vander, Louvain 1975, pp. 295-336; E. CORETH, Cuestiones fundamentales de hermenéutica, Herder, 1972, Barcelona 1972, pp. 31-59; P.-A. STUCKI, Hermeneutique et dialectique, Editions Labore et Fides, Montreux 1970, pp. 9-23.

62. «Gaudium et Spes», nn. 44, 33, 35, 38.

63. «...A través de este rodeo, la antropología teológica se hace toda ella solidaria de una cristología. Si Cristo es la verdad del hombre, tan solo el misterio de Cristo podrá esclarecer el misterio y la vocación del hombre. Éste es uno de los importante sentidos que las investigaciones antropológicas pueden tomar en este período todavía de su prehistoria». Cfr. Pierre WATTE, $A n$ - 
lo que pudiéramos llamar, la espiral hermenéutica de la antropología de salvación:

El Verbo de Dios por quien todo fue hecho, se encarnó, para que, hombre perfecto, salvara a todos y recapitulara todas las cosas. El Señor es el fin de la historia humana, punto de convergencia hacia el cual tienden los deseos de la historia y de la civilización, centro de la humanidad, gozo del corazón humano y plenitud total de sus aspiraciones. Él es aquel a quien el Padre resucitó, exaltó y colocó a su derecha, constituyéndole juez de vivos y muertos. Vivificados y reunidos en su Espíritu, caminamos como peregrinos hacia la consumación de la historia humana, la cual coincide plenamente con su amoroso designio: Restaurar en Cristo todo lo que hay en el cielo y en la tierra (Eph $1,10)^{64}$.

Se nota, como una especie de espiral hermenéutica. El hombre es tomado en su situación. La Iglesia, orienta e ilumina con sus principios evangélicos, con la finalidad de ayudar al hombre en su dimensión personal, social e histórica. A su vez, la Iglesia se enriquece con las adquisiciones del hombre y del mundo, que, al ser interpretadas como signos de los tiempos y, en acto último, ser confrontados con el máximo modelo Cristo, se convierten en una nueva fuerza activadora de las realidades terrenas positivas, para la humanización del hombre y de la historia. Con lo cual se logrará la construcción del Reino futuro - «reino eterno y universal; reino de verdad y de vida; reino de santidad y de gracia; reino de justicia, de amor y de paz»- ${ }^{65}$ ya, aquí, en nuestro acontecer mundano haciendo en la historia, la Historia de Salvación.

La antropología del Vaticano II, está enmarcada dentro del concepto predominante en la teología de esa época: el lugar preponderante del cristianismo dentro de la Historia de la Salvación ${ }^{66}$. La antropología de la «Gaudium et Spes» será por tanto, una antropología de salvación. El hombre es el centro de la Historia de la Salvación, puesto que Cristo es el centro y culmen de esa Historia. Y, precisamente, su actuar en la historia se debe al hombre tal como aparece en su circunstancia social e histórica. Así, el fin del Cosmos aparece como una historia del hombre ante Dios en Cristo.

tropología teológica y hermenéutica hamartiología en el siglo $X X$, en H. VORGRIMLER, y otros, t. III, BAC, Madrid 1974, p. 63.

64. «Gaudium et Spes», nn. 45, 38.

65. Id., n. 39 .

66. Historia; Historia de Salvación, en Sacramentum Mundi, Herder, Barcelona 1976, t. 1, Colum. 272-273, 281-286, 287-288. 


\section{B) Documentos Con MAtices ANTRopológicos Próximos A Puebla}

El mensaje de Pablo VI en la «Populorum Progressio» (1967), en la «Octogesima Adveniens» (1971) y en la «Evangelii Nuntiandi» va dirigido al hombre. Tenemos elementos antropológicos importantes que nos ayudarán a comprender mejor la concepción de Puebla sobre el hombre.

También, será interesante rastrear, las ideas antropológicas más resaltantes de Medellín, por ser el documento más importante de la visión cristiana desde América Latina que precede a Puebla.

\section{Mensaje antropológico de Pablo VI}

Pablo VI sigue, en algunos aspectos, la apertura de Juan XXIII, aunque no estaba imbuido como éste, de la hermenéutica de los «géneros literarios» y de un sano «historicismo», con lo cual había superado la teología aristotélicoescolástica. Sin embargo, en uno de los puntos que le sigue, acertadamente, es en la preocupación por el hombre y el mundo, sin distinción de razas ni credos, que tan decididamente había afrontado Juan XXIII en la «Mater et Magistra» (1961) y en la «Pacem in terris» (1963). «Había que conocer directamente el ambiente aristotélico-tomista que reinaba en las universidades pontificias de Roma para comprender lo que suponía la nueva postura de Juan XXIII» ${ }^{67}$.

En la «Populorum Progressio» y en la «Octogesima Adveniens», Pablo VI trata de interrogar a las antropologías modernas, para descubrir por dónde van las aspiraciones y la realización del hombre de hoy. Su intención es clara. Quiere partir del hombre, pero del hombre de hoy con sus azares, sus vaivenes, sus preocupaciones individuales, sociales, políticas, económicas, históricas, inmediatas y remotas y, poder así, lograr la conexión con el mensaje evangélico sobre el hombre y para el hombre ${ }^{68}$.

67. A. Turrado, De Juan XXIII a Juan Pablo II. Reflexiones en torno a la raíz de sus posturas doctrinal y práctica, en Rev. Agustiniana de Espiritualidad, vol. XX, nn. 61-62 (1979) 9-91; «...Los derechos humanos de todos eran para él algo sagrado e inalienable, y no podía comprender a ese hombre-especie de la cultura greco-romana, que tiende a aniquilar a las personas de «carne y hueso» en aras de la especie y de las instituciones creadas por el hombre». Cfr. Id., o.c., 1.c., p. 24 .

68. «...La Iglesia, «experta en humanidad» (Populorum Progressio), comienza no obstante su diálogo, preguntando a las antropologías modernas, para aprender en qué forma el hombre moderno, en su vida concreta y en su pensamiento, entiende los caminos de su realización. Esta sensibilidad acentuada hacia las dimensiones antropológicas se presenta como una conditio sine que non para ser escuchada por los hombres de hoy y ver acogido el mensaje evangélico». Cfr. J. Gevaert, Antropología y catequesis, Edic. Don Bosco CCS, Madrid 1975, p. 8; «La Populorum Progressio, Encíclica del humanismo como nos complace llamarla, se inserta en la gran corriente de pensadores humanistas que, especialmente en este siglo han querido dar respuesta coherente y 
La novedad de la antropología de la «Populorum Progressio» con relación a la «Gaudium et Spes», a quien sigue en los conceptos fundamentales, está en la proposición en favor del desarrollo integral del hombre y el desarrollo solidario de la humanidad ${ }^{69}$.

Hay dos aspectos principales, por tanto. El primero es el desarrollo integral del hombre ${ }^{70}$. Parte de la aspiración de los hombres de hoy a liberarse de la miseria, lograr seguridad en los medios para vivir, asumir las responsabilidades correspondientes a su ser humano, liberarse de toda opresión y afrenta a la dignidad de la persona humana para crecer en el ser más. El Papa resume en breves palabras lo que afecta al ser del hombre: «...hacer, conocer y tener más para ser más» ${ }^{71}$. Lo que constituye el fondo del hombre es el ser más y todo debe ir encaminado en una forma dinámica e integral a conseguir esta meta. Si cualquier otro de los elementos se ponen como meta, desequilibra el desarrollo integral del hombre y sobrepasa el punto clave, lo constitutivo que es el ser más. Esto hará que cualquier ideología o sistema que resalte uno de estos elementos sobre el ser más, afecte a la esencia del hombre y sea rechazado ${ }^{72}$.

El ser más supone un esfuerzo personal y responsable por superarse a sí mismo, trascenderse, abrirse a todos los valores auténticos, incluyendo el religioso pues en Cristo encontrará la total plenitud: «...Por su inserción en el Cristo vivo, el hombre tiene el camino abierto hacia un progreso nuevo, hacia

comprometida al hombre de hoy, con base en una visión del mundo y de la história. Un número representativo de «pensadores del humanismo nuevo» ha sido expresamente citado, como un implícito homenaje: el P. Lebret, quien por invitación del papa Pablo VI colaboró ampliamente en esta Carta, Maritain, Chenu, Nell Breuning, Mons. Larrin, H. de Lubac. Pero no parece arriesgada esta afirmación, el documento entierra sus raíces en otros pensadores. Personalmente encuentro numerosas coincidencias con Blondel y particularmente con los escritos de Mounier. Desde luego, siguiendo muy de cerca al Evangelio, Pablo VI se ha inspirado en el humanismo de los anteriores Pontífices y especialmente en la rica doctrina conciliar». Cfr. A. LÓPEZ, El hombre: un ser integral, Edic. Paulinas, Bogotá 1973, pp. 11-12.

69. «Por eso hoy dirigimos a todos este solemne llamamiento para una acción concreta en favor del desarrollo integral del hombre y del desarrollo solidario de la humanidad». Cfr. «Populorum Progressio», n. 5.

70. «Hay una relativa novedad en la Carta. Se utiliza el término «desarrollo», antes propiedad de economistas y sociólogos. Para nosotros «desarrollo» es aquí equivalente de humanismo, (integral o trascendental). Se emplea la expresión «desarrollo integral» en el sentido de universalidad, referente a «todos los hombre» de cada hombre a la humanidad entera. El concepto «Integral» tiene también otro sentido: no es algo que se puede reducir al simple crecimiento económico. «Se trata de construir un mundo donde todo hombre... pueda vivir una vida plenamente humana». Es el hombre entendido como capaz de crecer en humanidad, valer más, Ser más». Cfr. A. LÓPEZ, o.c., p. 38.

71. «Populorum Progressio», n. 6.

72. Id., nn. 26-31. 
una humanidad trascendental, que le da su mayor plenitud; tal es la finalidad suprema del desarrollo personal» ${ }^{73}$.

El otro aspecto, el desarrollo solidario de la humanidad, completa el desarrollo integral del hombre. Abarca la faceta social e histórica del hombre ${ }^{74}$. Èl crecimiento del hombre en su ser más, en su valer más, en humanidad es integral cuando lo político, lo económico, lo social, tanto en lo personal, en lo nacional como en lo internacional, está encaminado al total desarrollo humano, siendo cada uno agente de su libertad y respetuoso de los deberes y los derechos de los demás. El respeto a la libertad y a la justicia, el derecho a la participación, las reformas sociales son asuntos éticos que reclama el hombre de hoy con vehemencia y lós exige como parte importante de su realización social e histórica ${ }^{75}$. El sentido comunitario y social es un deber del hombre ${ }^{76}$. Y aquí se presenta algo característico que reclama la encíclica con novedad y fuerza: la propiedad privada no es un absoluto, tiene una función social; lo superfluo debe ponerse al servicio de los demás ${ }^{77}$.

El desarrollo solidario de la humanidad está sustentado en tres pilares: el deber de solidaridad, el deber de justicia social, el deber de caridad universal. La finalidad será conseguir «un mundo más humano para todos, en donde todos tengan que dar y recibir, sin que el progreso de los unos sea obstáculo para el desarrollo de los otros» ${ }^{78}$. Todo el desarrollo debe conducir al crecimiento del hombre y de la persona en la sociedad ${ }^{79}$.

Además del sentido social encontramos una connotación histórica: la solidaridad mundial debe llevar a los pueblos a ser artífices de su destino ${ }^{80}$. Pero también, aquí, aprovecha el Papa para remarcar la dimensión trascendente y salvadora que debe tener este actuar de los hombres y de los pueblos:

...una renovada toma de conciencia de las exigencias del mensaje evangélico obliga a la Iglesia a ponerse al servicio de los hombres, para ayudarles a captar todas las dimensiones de este grave problema y convencerles de la urgencia de una acción solidaria en este cambio decisivo de la historia de la humanidad ${ }^{81}$.

73. Id., nn. 16, 18, 15 .

74. J. Hoyos VASQueZ, La imagen del hombre en Puebla, en Theologica Xaveriana n. 51 (1979) 144.

75. «Populorum Progressio», nn. 6, 43, 12.

76. Id., n. 17.

77. Id., n. 23.

78. Id., n. 44.

79. Id., n. 34.

80. Id., n. 65 .

81. Id., nn. $1,59-80$. 
Y es que la Iglesia tiene una visión propia y global del hombre y de la humanidad con la cual puede ayudar al desarrollo integral del ser del hombre:

...La presente situación del mundo exige una acción de conjunto, que tenga como punto de partida una clara visión de todos los aspectos económicos, sociales, culturales y espirituales... la Iglesia... Fundada para establecer desde acá abajo el Reino de los cielos. Pero, viviendo en la historia, ella debe «escrutar a fondo los signos de los tiempos e interpretarlos a la luz del Evangelio». Tomando parte en las mejores aspiraciones de los hombres y sufriendo al no verlas satisfechas, desea ayudarles a conseguir su pleno desarrollo y esto porque ella les propone lo que ella posee, como propio: una visión global del hombre y de la humanidad ${ }^{82}$.

Por fin, hace a los pensadores modernos una invitación a buscar un humanismo nuevo para lograr una vida y un mundo más humanos, donde el hombre pueda desarrollarse plenamente en la plenitud de su ser integral ${ }^{83}$.

En esta Carta se nos propone que con el ser más y la apertura a lo social, a lo histórico y a lo espiritual; con el desarrollo integral del hombre y el desarrollo solidario de la humanidad, se logra el ser integral del hombre. Continúa la antropología de salvación de la «Gaudium et Spes»; pero con matices que van preparando una antropología liberadora. Aquí, podríamos calificarla como una antropología del desarrollo integral, de salvación integral, del ser integral.

En la «Octogesima Adveniens» pone, Pablo VI también, como centro del progreso humano, al hombre, pero se nota un avance, con respecto a lo social y a la actuación del hombre en la historia, en relación a la «Populorum Progressio». Condena al capitalismo liberal y al marxismo en la misma medida ${ }^{84}$. Son ideologías que atentan contra la dignidad del hombre, contra el ser del hombre; lo pone en claro con más fuerza que lo había hecho en la «Populorum Progressio» y no se contenta con abogar por un reformismo como había hecho en ésta ${ }^{85}$. Distingue entre ideologías y los movimientos que se originan de ellas. Las ideologías quedan estables como doctrinas, mientras que los movimientos originados por ellas, evolucionan y, a veces, tienen logros positivos que no se pueden menospreciar con tal de que estén conformes con los principios de la recta razón y las exigencias justas de la persona humana ${ }^{86}$.. Siempre

82. Id., n. 13.

83. Id., n. 21.

84. «Octogesima Adveniens», nn. 33-35.

85. «Populorum Progressio», n. 32.

86. «Pero fuera de este positivismo que reduce al hombre a una sola dimensión -importante, hoy día-y que en esto lo mutila, el cristiano encuentra en su acción movimientos históricos concretos nacidos de las ideologías y, por otra parte, distintos de ellas.... Por lo demás, en la medida en que estos movimientos van de acuerdo con los sanos principios de la razón y res- 
deben quedar a salvo los valores auténticos, en consecuencia, especialmente la libertad, la responsabilidad, la justicia social, la apertura a lo espiritual que son fundamentales para el progreso integral del hombre.

Hace una constatación la «Octogesima Adveniens»; el fracaso de las ideologías ha dado pie al resurgir de las utopías. Los sistemas originados por las ideologías predominantes como son el socialismo burocrático, el capitalismo tecnocrático, la democracia autoritaria no han resuelto el problema de la convivencia fraterna con justicia, libertad e igualdad y han engendrado el positivismo materialista y el egoísmo. Las utopías, entendidas con las debidas precauciones, pueden provocar la creatividad y orientar hacia la búsqueda de un futuro nuevo para el hombre, dando oportunidad para dirigir las fuerzas inventivas del espíritu y del corazón humano que alimentan la dinámica social, hacia un porvenir esperanzador y renovado. Aquí, también, tiene parte esa dimensión que el cristianismo, con su visión antropológica, quiere integrar en el hombre por considerarla constitutivo de él: en el corazón del mundo y del hombre actúa Dios ${ }^{87}$. En la constitución del hombre y en su actuar histórico entra de por medio Dios. Da un dinamismo que impele a superar todo sistema y toda ideología que dañe al hombre y a comprometerse en la construcción de un mundo donde reine la paz, la justicia, la fraternidad como preparación para futuro Reino de Dios desde acá, en esta tierra.

La «Octogesima Adveniens» asume el sentido positivo del progreso hacia el cual tiende la humanidad ${ }^{88}$. La cualidad sobre la cantidad, la verdad de las elaciones humanas, la participación, la responsabilidad, la comunicación, el saber, la cultura, el abrirse a los demás en actitud de servicio mutuo, la concordancia en una labor común son signos positivos que hay que tenerse en cuenta, sobre todo, si el cristiano alcanza a percibir el estar motivado por el

ponden a las justas aspiraciones de la persona humana ¿quién rehusaría reconocer en ellos elementos positivos y dignos de admiración? Cfr. «Octogesima Adveniens», n. 30.

87. «...El Espíritu del Señor que anima al hombre renovado en Cristo, cambia sin cesar los horizontes donde su inteligencia quiere encontrar su seguridad, y los límites donde su acción se encerraría de buena gana; le penetra una fuerza que le llama a superar todo sistema y toda ideología. En el corazón del mundo permanece el misterio del hombre que se descubre hijo de Dios en el curso de un proceso histórico y sicológico, donde luchan y se alternan presiones y libertad, gravedad del pecado y soplo del Espíritu.

El dinamismo de la fe cristiana triunfa entonces sobre los cálculos estrechos del egoísmo. Animado por el poder del Espíritu de Jesucristo, Salvador de los hombres, sostenido por la esperanza, el cristiano se compromete en la construcción de una ciudad humana, pacífica, justa y fraternal, que sea una ofrenda agradable a Dios. Efectivamte, «la esperanza de una tierra nueva no debe amortiguar, sino más bien avivar la preocupación de perfeccionar esta tłerra, donde crece el cuerpo de la nueva familia humana, el cual puede de alguna manera anticipar un vislumbre del siglo nuevo». Cfr. Id., n. 37.

88. Id., n. 47. 
centro del Reino que es Cristo: «...el impulso del Espíritu del Señor ayudan al hombre a situar su libertad creadora y agradecida, en la verdad de todo progreso y en la sola esperanza que no decepciona jamás» ${ }^{89}$.

Además, este progreso supone una justicia mayor que se logrará con el cambio de los corazones y de las estructuras ${ }^{90}$. Aquí encontramos un elemento nuevo del actuar del hombre en la historia que es un avance con relación a la «Populorum Progressio». El actuar del hombre en la historia supone un cambio de mentalidad en lo personal y de estructuras en lo social. La palabra liberación está, en este momento, claramente en la Encíclica —aunque sin mucho realce-, pero matizada en su significado: cambio de corazones y de estructuras pero desideologizado y con cariz de moral cristiana.

Finalmente, se pide un nivel creativo en la reflexión y, sobre todo, una acción decidida para encontrar los nuevos caminos que logren el progreso integral del hombre ${ }^{91}$.

El concepto de liberación que aparece en la «Octogesima Adveniens» y que había sido aireado por Medellín, lo precisa Pablo VI en la «Evangelii Nuntiandi» (1975). Quiere desideologizar la palabra liberación, recoger las adquisiciones positivas que han surgido en torno a ella y engarzarlas con las acepciones bíblicas de liberación, para hablar de una liberación integral en la cual se resume lo humano y la visión cristiana. Así, intenta abarcar todas las dimensiones del hombre ${ }^{92}$.

Esta Carta nos da una serie de rasgos con los cuales podemos calificar, de antropología de liberación evangélica, su concepción sobre el hombre, así como pudiéramos calificar de antropología del desarrollo integral del hombre en la «Populorum Progressio» y de antropología del progreso integral del hombre, en la «Octogesima Adveniens».

\section{Características antropológicas del Documento de Medellín (1968)}

La Segunda Conferencia General del episcopado latinoamericano, reunida en Medellín, se distingue por dar relevancia especial a la palabra liberación. $\mathrm{Su}$ origen lo tiene en el contexto socio-político y en la incipiente reflexión teológica latinoamericana, que se llamaría la Teología de la Liberación ${ }^{93}$.

\footnotetext{
89. Id., Ib.

90. Id., n. 45 .

91. Id., nn. 48-51.

92. «Evangelii Nunciandi».

93. «...Aquí se da el salto cualitativo y la ruptura explícita entre una visión del mundo ligada a una práctica «desarrollista» y otra ligada a una práctica de «liberación». El término «liberación» no es un término abstracto o académico, sino que surge de una práctica política bien precisa, tanto en el Perú como en el resto de América Latina... Ahora bien, todo este «mundo de desa-
} 
Hay un hecho básico de subdesarrollo, marginación, explotación, dominación, opresión que está a la vista de todos en América Latina. Al hablar de promoción humana, saltará a la vista inmediatamente, la necesidad de una acción en la sociedad y en el mundo. Esto implica solidaridad con los pobres y marginados, denuncia de las injusticias y necesidades de la reforma de estructuras ${ }^{94}$.

Sin embargo, no hay una antropología explícita en Medellín; ésta es una de las causas que origina diversas interpretaciones o lecturas de Medellín cada

rrollo» entraba entonces, en un proceso de acelerada crisis y desintegración. La «teoría de la dependencia» será la expresión teórica de la toma de conciencia del fracaso del modelo desarrollista. Por otro lado, el término «liberación» connotaba en toda América Latina también situaciones históricas bien concretas: en primer lugar la revolución cubana de 1959; revolución mexicana (1911), boliviana (1952), guatemalteca (1952), etc... El término «liberación» se ligaba también en América Latina al movimiento guerrillero... Cuando se hablaba de «liberación» se refería también a la práctica de muchos cristianos que... resistían y luchaban contra la dictadura... «Liberación» implicaba así una opción revolucionaria y una clara ruptura política e ideológica con el reformismo national-desarrollista y con los nuevos regímenes militares. Es en este contexto histórico concreto donde hay que entender el paso de la Teología del Desarrollo a una Teología de la $\mathrm{Li}$ beración, como se expresó en la conferencia de Chimbote de Gustavo Gutiérrez». Cfr. P. RICHARD, Desarrollo de la Teología en la Iglesia Latinoamericana, en E. Dussel, y otros, La Iglesia Latinoamericana de Medellín a Puebla, Cehila-Codecal, Bogotá 1979, pp. 63-64; «La II Conferencia General se situaba en el cruce de dos caminos. El desarrollismo en crisis y el compromiso profético-liberador que se había gestado desde el inicio del Concilio, por una parte, y desde la resistencia popular — que se radicaliza - contra el desarrollismo desde 1954... La teología desarrollista, de tipo europeo y progresista (hasta conciliar), no tenía, sin embargo, novedad. Por el contrario, la teología de la liberación estaba naciendo y pudo expresarse claramente. El grupo profético expresaba el sentir de las inmensas mayorías latinoamericanas. Los grupos conservadores estaban en retirada, sin teología que pudiera defender sus posiciones... Esto explica el por qué el CELAM desarrollará la teología de la liberación como su propia teología. El CELAM era una avanzadá profética en una Iglesia latinoamericana que en sus cuadros jerárquicos estaba lejos de asumir en mayoría esa posición. Pero el CELAM era fiel a la mayoría del pueblo latinoamericano, a buena parte del clero, de los militantes cristianos y del pueblo sumergido en su catolicismo popular.

Se tiene conciencia de que «estamos en el umbral de una nueva época histórica de nuestro continente, llena de un anhelo de emancipación total, de liberación de toda servidumbre, de maduración personal y de integración colectiva. Percibimos aquí los preanuncios en la dolorosa gestación de una nueva civilización» (Medellín, Introducción)». Cfr. E. Dussel, Dinámica de la opción de la Iglesia por los pobres (1968-1979), en Dussel y otros, o.c., pp. 13-14; La reflexión teológica estaba representada en Medellin, entre otros, por el representante máximo de la recién iniciada corriente de la teología de la liberación, Gustavo Gutiérrez y su influencia como perito se hizo notar. Cfr. H. PARAdA, Crónica de Medellín, Indo-American Press Service, Bogotá 1975, p. 255; La promovida por Paulo Freire en educación también tiene influencia en Medellín. «Se cree generalmente que soy yo el autor de este extraño vocablo concientización... En realidad, fue creado por un equipo de profesores de INSTITUTO SUPERIOR DE ESTUDIOS DEL BRASIL, Hacia los años 64; se puede citar entre ellos al filósofo Álvaro Pinto y al profesor Guerreiro.

...Pero fue Helder Cámara quien se encargó de difundirla y de traducirla al inglés y al francés. Cfr. P. Freire, Concientización. Teoría y práctica de la liberación, Asociación de Public. Educ. Bogotá 1972, p. 29.

94. Documento de Medellín, Justicia, n. 1; Paz, n. 1. 
una desde su ángulo de mira ${ }^{95}$. «Creo que la ausencia en Medellín de una visión cristiana del hombre, explícitamente abordada y reflejada, fue la causa de la ambigüedad en que nuestra pastoral se ha débatido durante diez años, situando la liberación de la persona humana en el ámbito de la conciencia personal o en el espacio de la existencia social exclusivamente» ${ }^{96}$.

Hay, no obstante, unas líneas antropológicas subyacentes que están marcadas por el contraste entre la «muerte del hombre», o mejor, por el «nohombre» -en expresión conocidísima de Gustavo Gutiérrez-, y la salvación liberadora ${ }^{97}$. La finalidad es construir una historia que sea de Salvación. Esto supone «una acción liberadora integral y de promoción del hombre en toda su dimensión, que tiene como único móvil el amor» ${ }^{98}$. El cristiano, con la gracia de Cristo renovado y hecho nueva criatura, tendrá un dinamismo nuevo. Será el hombre nuevo en Cristo, cuyo dinamismo fundado en el amor, impelerá al hombre a profundizar sus relaciones con Dios, la fraternidad con los hermanos y un nuevo modo de actuar en las cosas del mundo ${ }^{99}$.

Coge las características fundamentales de la antropología de salvación de la «Gaudium et Spes» y del ser integral de la «Populorum Progressio», con re-

95. «...El acento es deliberadamente puesto en 'lo religioso' sin olvido de la dimensión política, pero sin privilegiarla de tal modo que aparezca como la preocupación fundamental... La segunda corriente estructurada socio-teológicamente con evidente predominio del primer polo (socio-político) sin negar expresamente ciertos puntos de Medellín desplaza su centro de atención hacia lo político-conflictual pasando por la lectura propia del análisis marxista con sus imperativos... «A. López Trujillo, Las Teologías de la liberación en América Latina, en Diálogos en el Celam, Bogotá pp. 45-46. «Una primera lectura es la que llamamos lectura espiritualizante de Medellín; una segunda manera de acercarse a Medellín, en la misma línea de la primera, es desde una lectura progresista y pastoralista; y llamaremos lectura militante de Medellín...

...cuando simultáneamente tenemos en cuenta sus factores: a) una lectura desde la praxis del movimiento popular y de la Iglesia que nace de ese dinamismo; b) un esfuerzo de comprensión crítica desde los textos mismos de Medellín; c) una lectura desde la reflexión teológica de estos diez años de desarrollo de Iglesia Popular». Cfr. A. Cusianovich, Exégesis de textos doctrinales, en DusSEL, y otros, o.c., pp. 80-82.

96. A. do CARMo Chuiche, El hombre en Puebla, Col. Puebla, CELAM, Bogotá 1979, p. 16; «...Deberá, pues, tomar como punto de partida las conclusiones de Medellín, con todo lo que tienen de positivo, pero sin ignorar las incorrectas interpretaciones a veces hechas y que exigen sereno discernimiento, oportuna crítica y claras tomas de posición». Cfr. JUAN PABLo II, Discurso inaugural de la III Conferencia del Episcopado Latinoamericano, en Puebla, Coedición Secret. Nac. del Episc. Peruano, CEEC, Paulinas, Lima 1979, p. 7.

97. «La Iglesia europea afrontaba el problema de «fe-ciencia» y entraba en un proceso de secularización, des-clericalización y des-mitologización; La Iglesia latinoamericana afrontaba el problema «fe-revolución» y entraba en un proceso de liberación. En Europa la Iglesia era desafiada teológicamente por el ateísmo estructural a la sociedad moderna y su proclamación de la muerte de Dios. En América Latina la Iglesia era desafiada teológicamente por la explotación, el subdesarrollo que causaba la muerte del hombre. Cfr. E. Richard, o.c., p. 61.

98. Medellín, Justicia, n. 4; Paz, n. 14.

99. Id., Justicia, n. 4. 
lación a los elementos constitutivos del hombre, su sentido social, su dimensión trascendente, pero donde se nota un tono especial es en el actuar del hombre con el matiz de liberación integral muy remarcado. Y no una liberación en abstracto, sino del hombre latinoamericano que es tomado en sus circunstancias concretas a la luz de Cristo, pues centra «...su atención en el hombre de este continente, que vive un momento decisivo de su proceso histórico... ha «vuelto» hacia el hombre, consciente de que para conocer a Dios es necesario conocer al hombre.

La Iglesia ha buscado comprender este momento histórico del hombre latinoamericano a la luz de la Palabra, que es Cristo, en quien se manifiesta el misterio del hombre» ${ }^{100}$.

Podemos presentar, brevemente, los aspectos sobresalientes de cada uno de los apartados en que hemos dividido la antropología de Medellín.

En los elementos constitutivos del ser del hombre, toma partes fundamentales de la antropología de la «Gaudium et Spes». Sin embargo, resultan nuevos aspectos del enfoque que da Medellín, ya que no es una simple adaptación del Concilio Vaticano II a Latinoamérica, sino una reinterpretación de los textos magisteriales desde América Latina ${ }^{101}$.

Se nota rápidamente la insistencia en el quehacer más que en el ser del hombre, de tal forma que, aparece el hombre como un ser dinámico, agente y actuante liberadoramente en acción transformadora de la historia concreta de este Continente. Se tendrá en cuenta el ser del hombre, cuyo fundamento último es ser imagen de Dios como insistía la «Gaudium et Spes», así como la vocación humana, la dignidd del hombre, la promoción humana, la búsqueda de la verdad, la personalización, la actitud de servicio, la libertad, los derechos de las personas, la promoción integral del hombre ${ }^{102}$. Pero, al partir de la constatación de la destrucción del ser del hombre latinoamericano por la miseria, la ignorancia, la opresión, el hambre, el odio, el egoísmo, el pecado añaden un punto de vista que origina nuevas características. Y lo primero que declara Medellín es la intolerable injusticia en que vive este hombre ${ }^{103}$. Por eso

100. MEdellín, Introducción a las Conclusiones, n. 1.

101. «...Los textos magisteriales no son «aplicados» en América Latina, sino «reinterpretados» desde América Latina. Esta inversión es evidente en la Segunda Conferencia General del Episcopado Latinoamericano en Medellín (1968). La intención inicial de la conferencia se expresaba en su título oficial: «La Iglesia en la actual transformación de América Latina a la luz del Concilio». De hecho el resultado fue el inverso y su título debería ser: «La Iglesia del Concilio a la luz de la actual transformación de América Latina»..., ahora la Conferencia de Medellín no fue la aplicación del Concilio Vaticano II, sino su interpretación a partir de la realidad histórica latinoamericana». Cfr. P. RichARD, o.c., pp. 61-62.

102. Medellín, Justicia, nn. 3, 4, 5, 11, 14, 15, 16, 23; Id., Paz, n. 14; Id., Educación, nn. $2,14,21$.

103. Medellín, Justicia, n. 1. Id., Educación, n. 3. 
necesita liberarse ${ }^{104}$. Debe abocarse para ello a una profunda conversión que dará pie a un hombre nuevo justo, libre y responsable, reflexivo, activo, transformador de este mundo en un «Reino de justicia, de amor y de paz» ${ }^{105}$. El amor, como supremo mandato del Señor, «debe mover a los cristianos a realizar la justicia en el mundo, teniendo como fundamento la verdad y como signo la libertad» ${ }^{106}$. Supondrá «ser más en el gozo de su autorrealización por el servicio y el amor» ${ }^{107}$. Al mismo tiempo, necesita una concientización crítica, creativa, dialogante, comunitaria, histórica ${ }^{108}$. Una conciencia social sensible, realista, objetiva, capaz de percibir los problemas de la comunidad, de las estructuras sociales y predispuesta a los cambios necesarios con los cuales se transforme y perfeccione el mundo, al mismo tiempo que se vive la justicia ${ }^{109}$. El hombre, por tanto, no puede ser objeto sino agente de su propia historia ${ }^{110}$. El desarrollo integral del hombre comienza, en este Continente, por una educación liberadora que es la que convierte al educando en artífice, en sujeto de su propio desarrollo ${ }^{111}$. La educación liberadora debe ser creadora, personalizante, ayudar a tomar conciencia de la dignidad de la persona humana, favorecer la libre autodeterminación, promover el sentido comunitario, abierta al diálogo, amar los valores nacionales, integrarse en la unidad pluralista de nuestro Continente y del mundo y hacer la justicia. Por último, debe capacitar a las nuevas generaciones para el cambio permanente y orgánico que implica el desarrollo integral, «teniendo en cuenta que el hombre, es el responsable y el artífice principal de su éxito o su fracaso» ${ }^{112}$.

En la dimensión social, también, se nota un sentido activo y protagónico del hombre en las relaciones sociales, marcado con el deseo de hacer la justicia.

Hay hambre y sed de justicia ${ }^{113}$. La justicia es tema central en Medellín. Sin embargo, esta justicia debe hacerse con amor ${ }^{114}$. La justicia sin amor engendra el odio, destruye la libertad y las relaciones fraternales que deben reinar entre los hombres ${ }^{115}$. Para ello, hay que tener conciencia social, hábitos

104. Id., Justicia, nn. 3, 4.

105. Id., Justicia, n. 3.

106. Id., Justicia, n. 4.

107. Id., Educación, n. 4.

108. Id., Educación nn. 3, 5, 8.

109. Id., Justicia nn. 17, 3.

110. Id., Paz, n. 14.

111. Id., Educación, n. 8.

112. Ib.

113. Id., Justicia, nn. 3, 5.

114. Id., Justicia, nn. 4, 5; Id., Paz, n. 14.

115. Id., Justicia, n. 13. 
comunitarios de solidaridad, diálogo y convivencia entre todos los medios y grupos sociales; actitud de servicio, espíritu de integración creadora y valiente en favor de la comunidad, así como también del propio país ${ }^{116}$. Pero esta integración comunitaria no puede ser en una forma pasiva. Toda la población y, en especial, las clases populares tan marginadas han de tener «una participación receptiva y activa, creadora y decisiva, en la construcción de una sociedad» ${ }^{117}$. Mediante esta participación liberadora protagónica se lograrán, los cambios y las transformaciones al servicio del hombre y del bien común, en la familia, en las organizaciones de los profesionales y de los trabajadores, en las empresas y en la economía, en la industria y en todas las organizaciones sociales ${ }^{118}$. El sistema liberal capitalista y el marxista no tendrán cabida en esta sociedad, pues, ambos atentan contra la dignidad de la persona humana ${ }^{119}$. Sin embargo, la unidad de acción de los hombres que integran los diversos grupos sociales como agentes respetuosos de la libertad y realizadores de la justicia, lograrán la meta de una sociedad liberada y justa, al servicio del hombre, en una socialización entendida en libertad, justicia y solidaridad fraterna ${ }^{120}$. En este clima, se conseguirá, una activa y eficaz particitación -inclusive política - de los ciudadanos a favor de la comunidad ${ }^{121}$.

El sentido histórico liberador está latente en todos los aspectos de la antropología de Medellín. El hombre es agente y señor de la historia; de su historia y de la historia de su pueblo y del mundo. Es una historia liberadora que intenta realizar la justicia ${ }^{122}$.

La actuación del hombre en la historia y en la historia concreta latinoamericana, aparece como otro de los matices especiales de Medellín. La historia la puede cambiar y transformar el hombre. El hombre no es estático, ni está simplemente en el mundo, ni se contenta con la realización de su existencia, sino que puede perfeccionar la historia transformándola con los cambios adecuados para realizar la justicia pero con amor ${ }^{123}$. Le toca instaurar un orden justo donde los hombres puedan realizarse como hombres y sean sujetos agentes de su historia ${ }^{124}$. esta historia que se realiza en el tiempo, supone lucha, capacidad inventiva, conquista permanente, conversión de corazones, transfor-

\footnotetext{
116. Id., Justicia, nn. 7, 17; Id., Educación, nn. 23, 27.

117. Id., Justicia, n. 7.

118. Id., Justicia, nn. 8-17.

119. Id., Justicia, n. 10.

120. Id., Justicia, nn. 13, 15.

121. Id., Paz, n. 14; Educación, n. 8.

122. Id., Paz, n. 14; Id., Educación, n. 8.

123. Id., Justicia, nn. 3, 4; Id., Paz, n. 16.

124. Id., Paz, n. 14; Id., Educación, n. 8.
} 
mación de actitudes, cambio de estructuras ${ }^{125}$. Se evitará la violencia con «una conveniente toma de conciencia, una adecuada preparación y esa efectiva participación de todos, que la ignorancia y la condición de vida, a veces infrahumana, impiden hoy que sea asegurada» ${ }^{126}$. El esfuerzo mancomunado de los hombres convertirá a la sociedad y al mundo en una historia liberadora donde reine la justicia y la paz ${ }^{127}$.

La dimensión trascendente, aparece en Medellín, al revelar, continuamente, la conexión de lo humano con lo cristiano. Tanto la actuación histórica del hombre en el mundo, como su ser y sus relaciones sociales tienen su perfección y sentido último en Cristo.

A la situación de injusticia en que vive el hombre latinoamericano, le da la Iglesia un calificativo moral: es una situación de pecado ${ }^{128}$. Es necesaria la conversión de los corazones para realizar la justicia y la paz social y para tener los hombres nuevos -imagen y semejanza de Dios-, hombres perfectos siguiendo el modelo de Cristo, que actúen libre y responsablemente a la luz del Evangelio, con lo cual podremos alcanzar los cambios adecuados de estructuras ${ }^{129}$. Esta conversión supone la paz con Dios que «es el fundamento último de la paz interior y de la paz social» ${ }^{130}$. El amor, como supremo mandato del Señor, es el que impele a los cristianos a realizar la justicia y la paz. Cristo es el que da la paz, el amor, la fraternidad, la justicia, la liberación auténtica que el mundo no puede dar, pues es el que ha reconciliado a todos con el Padre y les motiva a realizar el Reino de Dios en este mundo ${ }^{131}$. Cristo es el que realiza la redención, liberando al hombre de todas las esclavitudes y promoviendo, íntegramente, todas sus posibilidades en todas sus dimensiones ${ }^{132}$. Pero el hombre no es pasivo en la historia; merced al don del Espíritu y con su autodeterminación, le toca hacer de esta historia una historia de Salvación, donde se dé una relación clara y profunda con Dios, donde aparezcan los hombres como hermanos y donde actúe el hombre en el mundo co-

125. Id., Justicia, n. 3; Id., Paz, n. 14.

126. Id., Paz, n. 15.

127. Id., Ib., 14.

128. Id., Justicia, n. 2; Id., Paz, n. 1; «...allí donde se encuentran injustas desigualdades sociales, políticas, económicas y culturales, hay rechazo del don de la paz del Señor; más aún, un rechazo del Señor mismo». Cfr. Id., Paz, n. 14.

129. Id., Justicia, n. 3; «...Cristo pascual «imagen de Dios invisible», es la meta que el designio de Dios establece al desarrollo del hombre, para que «alcancemos todos la estatura del hombre perfecto».

Por esto, todo «crecimiento en humanidad» nos acerca a reproducir la imagen del Hijo para que Él sea el primogénito entre muchos hermanos». Cfr. Id., Educación, n. 9.

130. Id., Paz, :n. 14.

131. Id., Paz, n. 14; Id., Justicia, n. 3.

132. Id., Justicia nn. 3, 4; Id., Educación, n. 9. 
mo señor y sujeto de la historia. No se confunde el progreso temporal con el reino de Cristo, sin embargo, el progreso temporal es un aspecto muy importante del Reino de Dios puesto en el perfeccionamiento de la sociedad humana querido por Dios. No obstante, el Reino de Dios es más amplio porque abarca, no solamente la dimensión temporal, sino también, la escatológica ${ }^{133}$.

Resulta, pues, en Medellín una antropología de salvación liberadora ya que no se queda en una liberación material, positivista y puramente temporal, sino que quiere aglutinar todas las dimensiones del hombre, pues «toda liberación es ya un anticipo de la plena redención de Cristo» ${ }^{134}$. Y, así, la acción de Dios en la Historia de la Salvación se convierte en acción de liberación integral a favor del hombre en todas sus dimensiones, teniendo «como único móvil el amor» ${ }^{135}$. Consiguientemente, no tenemos temor en calificar de antropología de salvación liberadora, las líneas sobre el hombre que aparecen en Medellín.

A pesar de lo dicho, sin embargo hay que tener en cuenta las lecturas que se han hecho de Medellín y las diversas interpretaciones a que ha dado lugar. Por eso, Puebla ha querido precisar la visión sobre el hombre para intentar corregir ambigüedades.

Eugenio ALONSO ROMÁN

133. Id., Justicia, n. 5.

134. Id., Educación, n. 9.

135. «Sólo a la luz de Cristo se esclarece verdaderamente el misterio del hombre. En la Historia de la Salvación la obra divina es una acción de liberación integral y de promoción del hombre en toda su dimensión, que tiene como único móvil el amor». Cfr. Id., Justicia, n. 4. 